\title{
Reflets
}

Revue ontaroise d'intervention sociale et communautaire

\section{Les jeunes et le travail}

BOURDON, Sylvain, et Mircea VULTUR (sous la direction de), Les jeunes et le travail, Saint-Nicolas, Presses de l'Université Laval et Éditions de l'IQRC, série Analyses et Essais, 2007, 308 p.

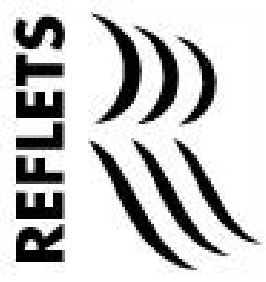

\section{André Samson}

Volume 14, numéro 1, 2008

Travail, jeunesse et intervention

URI : https://id.erudit.org/iderudit/018863ar

Aller au sommaire du numéro

Éditeur(s)

Reflets : Revue d'intervention sociale et communautaire

ISSN

1203-4576 (imprimé)

1712-8498 (numérique)

Découvrir la revue

Citer ce compte rendu

Samson, A. (2008). Compte rendu de [Les jeunes et le travail / BOURDON, Sylvain, et Mircea VULTUR (sous la direction de), Les jeunes et le travail, Saint-Nicolas, Presses de l'Université Laval et Éditions de l'IQRC, série Analyses et Essais, 2007, 308 p.] Reflets, 14(1), 250-252.

Tous droits réservés ( Reflets : Revue d'intervention sociale et communautaire, Ce document est protégé par la loi sur le droit d’auteur. L’utilisation des 2008 services d’Érudit (y compris la reproduction) est assujettie à sa politique d'utilisation que vous pouvez consulter en ligne.

https://apropos.erudit.org/fr/usagers/politique-dutilisation/ 


\title{
Les jeunes et le travail
}

\section{BOURDON, Sylvain, et Mircea VULTUR (sous la direction de) 2007,} Saint-Nicolas, Presses de l'Université Laval et Éditions de l'IQRC, série Analyses et Essais, 308 p.

\author{
Par André Samson, Ph.D., \\ Faculté d'éducation, Université d'Ottawa
}

Comme son titre l'indique, ce livre aborde la problématique de la réalité du travail chez les jeunes. Sous l'égide de l'Observatoire jeunes et sociétés, Sylvain Bourdon et Mircea Vultur ont réuni plusieurs chercheurs qui proviennent de différents champs, comme les sciences sociales, l'éducation ou l'orientation scolaire et professionnelle. L'ouvrage se divise en trois parties : la première aborde les parcours professionnels et le travail, la deuxième approfondit l'insertion professionnelle et le lien entre les études et la troisième partie décrit les milieux de travail et les conditions d'emploi.

Parmi les thèmes abordés tout au long de la première partie, notons le texte de Marc Molgat. Ce dernier traite de la question du rôle des parents chez les jeunes décrocheurs. Déjà, la recherche a très bien démontré que les parents exercent une l'influence centrale sur le choix et le développement de carrière de leurs enfants. Plus particulièrement, Molgat situe sa recherche dans un contexte de cheminement professionnel difficile. L'auteur procède à l'inventaire et à la description de différentes formes d'interventions parentales et il tente d'en décrire les possibles conséquences sur le parcours professionnel de leurs jeunes. De son côté, Liette Goyer centre sa contribution autour de la pratique $\mathrm{du}$ counselling d'orientation scolaire et professionnelle auprès des jeunes. Selon Goyer, ce type de pratique doit se dérouler dans le temps. En effet, comme le rapport au travail évolue selon les expériences, il en va de même pour l'orientation scolaire 
et professionnelle. Cette pratique doit s'ajuster au cumul des expériences de travail vécues par les jeunes.

La deuxième partie de l'ouvrage aborde la question de l'insertion professionnelle et le lien entre les études et le travail. L'article deVultur décrit très bien comment les jeunes s'adaptent aux multiples exigences des entreprises, et ce, afin de décrocher un travail rémunéré. Par exemple, certains quittent les bancs de l'école afin d'acquérir une nécessaire expérience alors que d'autres vont cumuler un travail avec un programme d'études. Selon Vultur, l'accession au marché du travail exige un effort d'adaptation et de créativité afin de satisfaire les critères de sélection des employeurs.

De leur côté, Claude Trottier et Madeleine Gauthier s'attardent au vécu des jeunes décrocheurs qui ont abandonné l'école avant l'obtention de leur diplôme d'études secondaires. Les deux chercheurs démontrent très bien que ces jeunes demeurent, jusqu'à un certain point, les acteurs de leur existence. Cette conclusion peut sembler surprenante, mais Trottier et Gauthier visent à dissoudre certains lieux communs qui peuvent fausser la perception du vécu de ces jeunes.

La troisième et dernière partie porte sur les milieux de travail et les conditions d'emploi. Dans un contexte de mondialisation et de précarisation du travail, la communication de Jean Bernier est particulièrement intéressante. En effet, cet auteur étudie l'impact des nouvelles formes d'emploi. Parmi ces nouvelles formes, notons le travail atypique, le travail occasionnel, à temps partiel, sur appel ou à durée déterminée. Comme on le sait, ces nouvelles formes d'emploi ajoutent à la précarité du travail. Ces deux problématiques ont exercé une pression à la baisse sur la rémunération et ont rétréci la couverture de la protection sociale. Pour éviter un élargissement continuel et trop important de la cassure sociale entre les jeunes et les générations précédentes, l'auteur propose certaines pistes de solution.

La postface de Daniel Mercure décrit très bien les différents parcours professionnels vécus par les jeunes d'aujourd'hui. Si autrefois la carrière pouvait être comparée à un long fleuve 
tranquille où tout était prévisible, ce n'est plus le cas dans un contexte de mondialisation. Le travail est devenu précaire et les jeunes doivent s'attendre à vivre plusieurs transitions de carrière. L'emploi à vie est une réalité du passé. Le "chaos vocationnel " constitue la norme et les jeunes sont et seront appelés à vivre de nombreuses transitions constituées de temps d'arrêt, de formation et de retour sur le marché du travail.

En somme, il s'agit d'un très bon ouvrage. L'apport des différents chercheurs permet de brosser un tableau très complet de la réalité du travail vécue par les jeunes. L'ensemble de ces articles informe, favorise la réflexion et permet au lecteur de développer une perception riche et ample du phénomène étudié. 